\title{
Non-consultant psychiatrists' knowledge of emergency detention procedures in Scotland
}

\section{A national survey}

\author{
Martin S. Humphreys
}

There is growing concern with psychiatrists' knowledge of mental health low, in particular with the introduction of new legistation and more complex statutory arrangements for after care. Desplte this, little systematic research has been undertaken in the UK. This study was designed to determine the knowledge of a sample of doctors in psychiatiry in Scotiand, of part of the Mental Health (Scotland) Act 1984 which provides for urgent involuntary admission to hosplital. A one in three sample of all non-consultant grade psychiatrists throughout Scotland was interviewed on the aspects of the Act considered essential to lawtul detention. Knowledge of even this restricted part of the Act was poor regardless of experience. Evidence emerged which suggested that at times clvil liberties might be compromised or the right to treatment denied. The findings clearty point to the need for increased emphasis on training in mental health law.

The mentally unwell are set apart from the majority of those with other forms of illness by the very nature of the disorder from which they suffer, which can impair insight and affect judgement. This in turn may lead to the necessity for confinement and treatment against the patient's expressed wishes, one of the reasons for the existence of a specific legal framework governing compulsory measures of care in such circumstances.

Civil commitment standards throughout much of the world are enshrined in statutory law. Doctors who detain patients in hospital or treat them there against their will are bound by the requirement of such provision despite any other considerations. There has been concern recently that the knowledge of doctors, in particular psychiatrists, who enforce mental health legisla- tion in Britain may be inadequate (Eastman, 1994) and that this might not only lead to infringement of civil liberties, but loss of the right to treatment. Active moves have been made to explore ways of improving matters and to formalise training for juniors and consultants in psychiatry, as well as general practitioners (Caldicott \& Mann, 1994).

Despite this there has been little systematic research into what doctors in the UK know, and do not know, about mental health law. It could be argued that this issue is particularly important where the civil rights of the patient are least well protected. One such situation is that of the 'emergency recommendation' in Scotland. This allows, given certain specific circumstances and conditions, for the urgent compulsory admission to hospital of a mentally disordered individual on the basis of a decision by any single fully registered medical practitioner, with the requirement that the consent of a third party be obtained 'where practicable' (S24/5 Mental Health (Scotland) Act 1984). In contrast to the situation in England and Wales, where compulsory admission under the similar, although not identical provision made by Sections 4 and 5 of the Mental Health Act 1983, is relatively uncommon, the emergency recommendation has become the most frequently used means of formal commitment to hospital in Scotland, with over 3000 episodes each year. These are not uncommonly initiated by the most inexperienced trainee psychiatrists, GPs or even doctors in medical, surgical or other specialities (Humphreys, 1992), often outside normal working hours and with less immediate access to the advice of a specialist senior colleague. In addition 
there is no direct access to a 28-day treatment order. Given this situation and the findings from an earlier more limited study (Humphreys, 1994), a national survey was undertaken to determine the knowledge of trainee and all other non-consultant grade psychiatrists working throughout Scotland of this relatively uncomplicated but important part of the current Act.

\section{The study}

A one in three random sample of all trainee and other non-consultant grade psychiatrists was selected region by region for the whole of Scotland. Each of these doctors was then contacted and asked to participate in the study. Those who agreed were interviewed on the specific terms of the provision made in the Mental Health (Scotland) Act 1984 for emergency compulsory detention, using a specifically designed questionnaire (Humphreys, 1994). No leading questions were asked but the nature of the interviews allowed the researcher to clarify any points raised and avoid ambiguity. Subjects were asked if they had received specific training in the use of urgent formal admission procedures, what had been their main source of information otherwise, and whether they had ever read the relevant part of the Act.

\section{Findings}

Of the 107 doctors originally selected 101 were interviewed. Four, all senior house officers, could not be contacted despite repeated attempts. Another had no previous experience with the Scottish Act and was working as a short-term locum in conditions of special security where the use of an emergency order would have been inappropriate. Only one senior house officer declined to participate. Doctors working in all sub-specialities were included and all grades and levels of experience were represented. There were 23 senior registrars, 27 registrars, 33 senior house officers in psychiatry and 11 general practice trainees. The sample included several people in flexible schemes. Those not in designated training posts included three clinical assistants, three staff grade psychiatrists and an associate specialist. There were almost equal numbers of male and female senior registrars and registrars, and in other grades a female to male ratio of approximately three to one. Experience in psychiatry ranged from one month to eight years among the training grade doctors, and up to 14 years in the case of one clinical assistant. All those in higher specialist training were members of the Royal College of Psychiatrists, as well as 12 of those holding registrar posts. In addition the remaining 15 registrars and eight senior house officers had passed Part I of the MRCPsych examination. All of those interviewed were working in circumstances where they may have been required to assess the need for urgent admission to hospital and detain the patient there immediately if necessary.

Table 1 shows the percentage of subjects in each group who answered particular questions correctly and in each case the overall figure for the entire sample. In addition participants were asked at what point in time the emergency order commenced, what powers it conferred and how long its effects lasted. The majority $(97 \%)$ of those interviewed were aware that the recommendation allowed for a period of detention of up to 72 hours. However, $50 \%$ incorrectly believed that the order took effect immediately the detaining doctor signed the requisite form rather than at the time of admission to hospital. Seventeen per cent said that the emergency recommendation made specific provision for treatment against the patient's will, while a further $22 \%$ did not know or were unsure. Thirty per cent believed that intoxication with alcohol or drugs was sufficient to prevent compulsory measures from being used. Twenty per cent stated that psychopathy or personality disorder, and $8 \%$ that a learning disability or some form of intellectual impairment, were specifically precluded from being grounds for detention. Sixtyseven per cent stated that they had had no formal training in the use of the emergency order and less than half of all those interviewed had ever read any part of the Act itself.

\section{Comment}

While this study is by no means unique it is the first of its kind to be undertaken in the UK. In view of the proportion of all junior psychiatrists in Scotland involved, the size of the sample and the $94 \%$ uptake rate, it is likely that it accurately represents what this group know about one specific area of current mental health legislation. The evident lack of knowledge, in the main irrespective of seniority, is of particular concern as the emergency recommendation is not only the part of the Act most frequently used by these doctors, but is also relatively straightforward and easy to understand. In spite of this none of the individuals interviewed was able to give an accurate description of all the conditions which must be fulfilled in order to detain a patient in an emergency. Only one question, about how long the period of detention lasted, was answered correctly by more than half the total sample. The most senior trainees alone succeeded in doing 
Table 1. Percentages of each grade of doctor, and of the whole sample, giving correct answers

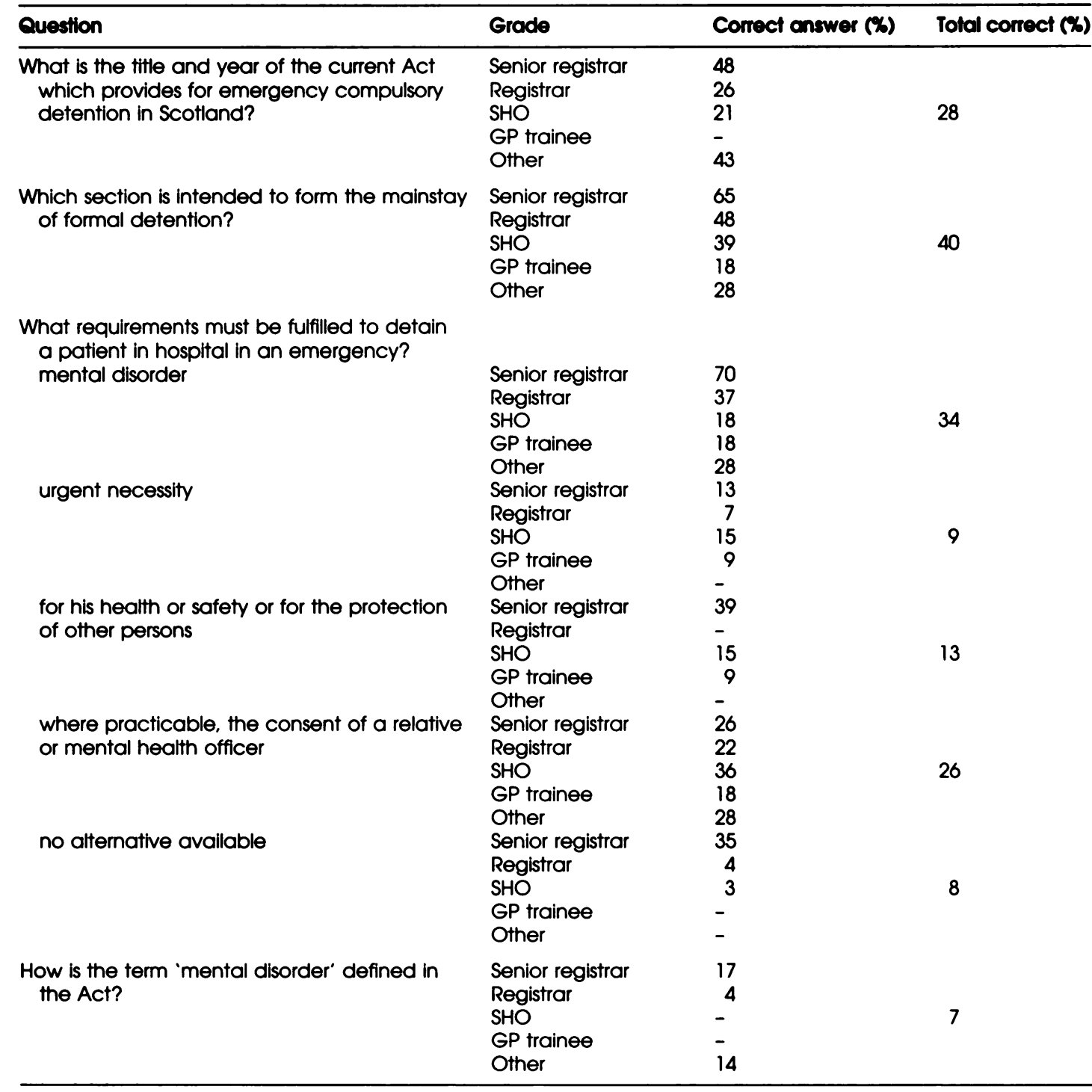

this in just two more instances, citing the presence of mental disorder as a prerequisite for detention and being aware that the emergency recommendation was not primarily intended to be the mainstay of formal hospitalisation. Of the remainder, fewer than $50 \%$ were right in each case. Some questions originally included, relating to the concept of treatability and restrictions on how soon one emergency order might follow on from another, were eventually discarded as there was such universal lack of understanding.

These findings are not peculiar to Scotland (Peske \& Wintrob, 1974) or even confined to psychiatrists. Even though there was only a small number of general practice trainees among the current sample there is evidence that their lack of understanding and knowledge may be part of a more general pattern (Humphreys \& Ryman, 1996). The results of the present study are similar in some respects, although actually compare poorly in others, to those from a previous, more circumscribed, study of trainees working in only one part of the country (Humphreys, 1994). As such they are a cause for concern in a jurisdiction where the decision to remove an individual's liberty may be taken by a single doctor. There is evidence that in making 
decisions about compulsory commitment to hospital medical practitioners do stay within the bounds of the statutory provision, although not necessarily by design, and generally act in the best interests of the patient (Soothill et al, 1990). Nevertheless, substantial numbers of those interviewed here not only showed a lack of understanding of what circumstances were necessary to justify the use of involuntary measures, but held the mistaken belief that under some circumstances, in particular when a patient was intoxicated, the law prevented them from being detained. The same was true to a lesser extent of other conditions which were mentioned, namely psychopathy, personality disorder and learning disability, none of which are in fact specifically precluded as grounds for detention. It is easy to see how such misunderstanding might lead to patients who may very well need to be in hospital being denied the right to treatment. There were those who thought that emergency detention entitled them to enforce treatment, which is not the case. Only one in four of the sample mentioned the requirement for consent to be obtained for emergency detention. This may indicate ignorance but also perhaps misinterpretation of the relevant passage of the Act, with doctors believing that the involvement of a third party is only needed where practicable rather than being a specific requirement. More importantly it might reflect a tendency to view the involvement of a third party with some resentment and as unnecessary or intrusive when what is thought to be the right decision has already been made by a medical practitioner (Deering, 1994).

Schwartz et al (1984) have suggested that doctors act on the basis of perceived patient need rather than that of a purely civil rights orientated approach and the findings reported here may mirror that. Affleck et al (1978) obtained such poor response rates in a comparative study of two groups of psychiatrists working in different parts of the USA that they concluded this might reflect indifference on the part of these practitioners to the legal aspects of compulsory detention. In keeping with this, nearly $60 \%$ of those interviewed in the present study stated that they had never read, or in some cases even seen a copy of the Act, and for the most part seemed unashamed of the fact. Of perhaps even greater concern was the possibility that there might still be those willing to use compulsory measures as a means of social control rather than a route to necessary treatment for some mentally ill people, with little regard for legal requirements and safeguards (Humphreys \& Geddes, 1994).

It is unlikely that the results of the present study simply reflect local patterns. They relate to a well circumscribed part of the Act concerning compulsory care of the mentally disordered in a particular jurisdiction and one might have expected the doctors concerned, who in most cases would have dealt frequently with patients detained as a result of the emergency recommendation, to be more, rather than less, familiar with the various statutory requirements when compared to other more complex areas of the legislation. However, superficial familiarity and frequency of use of this form of detention could have engendered complacency.

\section{Conclusions}

A striking feature of the present work, as well as the lack of knowledge exposed, was how few of those interviewed had received any formal teaching in the application of the emergency powers. something which could be interpreted as indifference to the wider issues and implications of the use of compulsion. Education is the obvious area in which improvement might be most readily effected and there is a clear need to address this at an early stage in psychiatric training. Change in attitude to the use of involuntary measures also seems likely to be required but may be more difficult to achieve. Mental health laws exist to ensure the protection of the rights of patients as well as those seeking to provide care and treatment for them. If doctors do not fully understand their use they fail not only in their statutory duty but risk compromising standards of practice and do their patients a grave disservice.

\section{Acknowledgements}

I thank all the doctors who took part in this study and the Chief Scientist's Office of the Scottish Office Home and Health Department for funding the project.

\section{References}

Affleck, G. G., Peske, M. A. \& Wintrob, R. M. (1978) Psychiatrists' familiarity with legal statutes governing emergency involuntary hospitalisation. American Journal of Psychiatry. 135. 205-209.

CaldicotT, F. \& MANN, S. (1994) Mental health law. British Medical Journal, 308, 408-409.

DEERING. A. (1994) Consent to emergency detention in Edinburgh. Psychiatric Bulletin, 18, 282-284.

EASTMAN, N. (1994) Mental health law: civil liberties and the principle of reciprocity. British Medical Journal, 308. 43-45.

HUMPHREYS, M. S. (1992) Persuasion, coercion, medical paternalism or the Mental Health Act: the dilemma of detention in a general hospital. Scottish Medical Journal, 37, 146-148. 
- (1994) Junior psychiatrists and emergency compulsory detention in Scotland. International Journal of Law and Psychiatry, 17, 421-429.

- \& GEDDES, J. (1994) Mental health law. British Medical Journal, 308, 857.

- \& RYMAN, A. (1996) Knowledge of emergency compulsory detention procedures among general practitioners in Edinburgh. British Medical Joumal 312. 1462-1463.

PESKE, M. A. \& WINTROB, R. M. (1974) Emergency commitment - a transcultural study. American Jouma of Psychiatry. 131. 36-40.
SCHWARTZ, H. I., APPELBAUM, P. S. \& KAPLAN, R. D. (1984) Clinical judgements in the decision to commit. Psychiatric discretion and the law. Archives of General Psychiatry, 41, 811-815.

SOOTHILL, K. KuPTUKSA, P. \& MACMIILAN, J. F. (1990) Compulsory hospital admissions: dangerous decisions? Medicine, Science and the Law, 30, 17-25.

Martin S. Humphreys, Senior lecturer in Forensic Psychiatry, Reaside Clinic, Birmingham Great Park, Rubery, Birmingham B45 9BE 